\title{
Insurgent Vulnerability and the Carbon Footprint of Gender
}

\section{By Stacy Alaimo}

Gendered stances, styles, practices, and modes of thought permeate the representations of the science of climate change, the activist response to climate change, and modes of consumerism responsible for releasing massive quantities of carbon into the atmosphere. This article critiques the masculinity of aggressive consumption that has increased the carbon footprint of the U.S. and the freefloating, transcendent perspective presented by the official U.S. accounts of climate change.

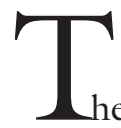

he Gendering Climate and Sustainabilityl conference poster features the stunning artwork of Kirsten Justesen [Front-cover]. The sheer aesthetic power of this image is remarkable - the radiant light, the interplay of blue and white, the translucent yet solid surfaces of ice. Justesen has staged other works involving ice, including the Melting Time series she created in Greenland in 1980, before the recognition of global climate change. She states in an interview: "The environmental and political aspect of these works has been growing in proportion to the consciousness of global warming. That was not my intention in 1980" (Adler 2008). It would be difficult now, however, given the growing consciousness of climate change, not to read Justesen's Ice Pedestal series in that context. The melting pedestal evokes the massive glacial thawing caused by global warming. All that is solid melts away and the very ground disappears - the arctic, the seacoasts, even entire island nations. The 
performances pair melting ice with human flesh suggesting the mutual vulnerability of both planet and people. Her nakedness bespeaks human exposure, an openness to the material world in which we are immersed. Justesen has said that her work investigates "meeting points for surfaces using [her] body as a tool" (Adler 2008). As flesh meets ice it usually recoils, but here, in the stillness of the photos, human flesh remains in contact with chilly reality. The figure in Ice Pedestal \#2 embraces the pedestal, exhibiting protection and care, even in the midst of its own vulnerability exhibited by the 'child's pose'. Whereas the naked body performs vulnerability, the thick black boots and gloves punctuate the performance with insurgence and strength. The stance of the figure in Ice Pedestal \#3 is selfprotective, with arms crossed in front of the body. As the figure's hair blends perfectly with the ice, however, the image suggests that defending oneself and defending the environment are the selfsame gesture, extending body to place. In short, the Ice Pedestal series embodies a quintessentially feminist stance toward environmentalism an insistence on what I call 'trans-corporeality'la - the recognition of the substantial interconnections between human corporeality and the more-than-human world. Despite its emphasis on embodiment, transcorporeality is not a phenomenological or individualistic stance. Tracing the material interchanges between bodies and global environmental, political, and economic systems requires access to scientific knowledge even as it provokes recognition that those very knowledges are shaped - and sometimes distorted - by political forces. Indeed it would not be possible to re-read Justesen's work as a performance of transcorporeality without some cognizance of the science, politics, and popular images of global climate change.

I would like to propose that vulnerability - a sense of precarious, corporeal openness to the material world - can foster an envi- ronmental ethics. It is a particularly feminist ethics in that it has origins in body politics. In fact, the performance of exactly this sort of naked vulnerability has emerged worldwide in the naked protest movement promoted by such groups as Bare Witness and Baring Witness. The fact that the naked protests - against genetically modified foods, war, animal cruelty, and global warming - include both men and women does not preclude their feminist lineage. When Spencer Tunick, for example, posed hundreds of people on a melting iceberg to protest global warming the term used to articulate people and place on the Greenpeace website's account of this event was 'vulnerability':

Without clothes, the human body is vulnerable, exposed, its life or death at the whim of the elements. Global warming is stripping away our glaciers and leaving our entire planet vulnerable to extreme weather, floods, sealevel rise, global decreases in carrying capacity and agricultural production, fresh water shortages, disease and mass human dislocations ("600 Strip Naked" 2007).

While it may be tempting to discount naked protesting as an easy way to gain publicity, casting it as just another spectacle in our media-saturated age, the naked protests do something more. When they disrobe, protesters momentarily cast off the boundaries of the human, allowing us to imagine corporeality not as a ground of static substance but as a place of possible connections, interconnections, and ethical becomings. They perform vulnerability as a trans-corporeal condition, in which the material interchanges between human bodies, geographical places, and vast networks of power provoke ethical and political actions. ${ }^{2}$ These performances declare that humans are not outside the planet looking in, not floating above the phenomena of climate change, but instead, that we are always materially interconnected to planetary 
processes as they emerge in particular places. Justesen's performance art and the global naked protests movements perform an insurgent vulnerability - a recognition of our material interconnection with the wider environment that impels ethical and political responses. The sense of substantial interconnection with the world may also motivate a continuing engagement with scientific knowledges that have become even more necessary for the formation of practices and policies that will foster the survival of human and nonhuman life on this planet. ${ }^{3}$ Insurgent vulnerability may be part of a feminist response to global climate change, especially insofar as it counters the hegemonic masculinity of aggressive consumption, as well as transcendent scientific visions.

\section{THE CARBON FOOTPRINT OF MASCULINIST CONSUMERISM}

Whereas trans-corporeality blurs the boundaries of the human as such, insisting that we are part of the material interchanges of the world, a peculiar sort of hypermasculinity of impervious but penetrating subjects has emerged in the United States. The U. S., which is, per capita, most responsible for global climate change has under the Bush regime been infamous for its swaggeringly dismissive attitude toward this staggering crisis. Although Bonnie Mann, in her article, How America Justifies Its War: A Modern/Postmodern Aesthetics of Masculinity and Sovereignty (Mann 2006) does not discuss climate change or other environmental problems, I suspect the hypermasculine style that she diagnoses has been fuelled not only by the pervasive post 9/11 fear of terrorist attacks, but also by a lurking, though repressed, dread of climate change and other environmental disasters. Such a posture, or as Mann puts it, such a 'style' of masculine, impenetrable aggression, has been evident in Bush's refusal to acknowledge, until recently, the threat of global warming. But the desire for hypermasculine 'hard bodies', in Susan Jeffords' term (Jeffords 1994) has also emerged as a consumer phenomenon that has increased U.S. carbon emissions. If, as Jeffords argues, the "indefatigable, muscular, invincible masculine body became the linchpin of the Reagan imaginary," (Jeffords 1994: 25), a similar, rigidly masculine corporeality characterizes the Bush Jr. era, a nationalistic stance of impenetrable masculinity that serves only to exacerbates the climate crisis.

I live, not exactly by choice, in the belly of the most ravenous, least sustainable, beast - not just the U. S. but Texas. It is well known that the U. S. gulps down far more than our share of fossil fuels. In Texas, especially, it is difficult to ignore the parodically hypermasculine modes of consumerism in which bigger is better. 'McMansions' have mushroomed as urban and suburban sprawl devours formerly open spaces and agricultural land. Since 1950 the average number of people living in a U.S. house has diminished by one person yet the size of the average American house "has more than doubled" (Adler 2006). Architect Ann Surchin points to a fearful populace: "No one knows when the next 9/11 will happen. And these houses represent safety - and the bigger the house, the bigger the fortress" (cited in Adler 2006). Even more noticeable, perhaps, is the fact that SUVs and pickup trucks have not only grown ridiculously huge, but they sport an obvious attitude of aggressive impenetrability, covered, as they often are, with armorlike accoutrements. Even more strangely, some of these vehicles sport decals of 'pissing contests' between Ford and Chevrolet owners, in which a boy urinates on the other brand's symbol. And, if that isn't evidence enough of a hypermasculine, hyperconsumerist attitude consider this: some trucks sport huge metal testicles that hang from the trailer hitch. One web site hawks a special set that was modeled after a "real brahma bull." The photo displays the well- 
endowed truck next to a Texas longhorn. This U.S. trend of living and traveling within rugged, impervious enclosures, as well as other modes of jacked-up consumerism, have contributed to global climate change as well to as the recent global financial collapse. ${ }^{4}$

Analyzing this overconsumption in terms of a gender-which isn't difficult given the giant testicles attached to the trucks - enables linkages to what Bonnie Mann has called a 'militarized masculine aesthetic'. Mann begins her provocative essay, How America Justifies Its War: A Modern/Postmodern Aesthetics of Masculinity and Sovereignty by questioning why, despite the fact that all ostensible justifications that Bush gave for the U.S. War in Iraq were exposed as being untrue, there has been "no decisive public outcry, no mass demonstrations [that] rock the capital, no credible popular uprising demand[ing] Bush's resignation for initiating a war without reasons" (Mann 2006:148). Mann boldly agues that an aesthetic of the "remaking of an American manhood" (Mann 2006:149) garnered support for the war. Discussing the infamous photos from Abu Ghraib, in particular the photos of Lynndie England, the woman humiliating Iraqi prisoners, Mann argues:

Here the American woman is given the phallus in true (postmodern) democratic form as the military takes up the practice of racialized gender bending. She is invited to participate in the militarized masculine aesthetic along with the men, to become the one who penetrates the racialized other... In this quintessentially modern, quintessentially postmodern military-technological aesthetic, all Americans are part of the hypermasculinized, but dispersed and systematized technomilitary subject of sublime experience (Mann 2006:159).

The fact that women may occupy this "national masculinity" is hardly a liberatory or laudable form of gender transgression. This sort of colonizing gender-bending is hardly a gay-affirmative or feminist stance. Indeed, this shameful moment in U.S. history demonstrates the post-Marxist cultural studies contention that nearly anything can be articulated, or connected, with anything else - here queer practices of a woman taking up the phallus have been enlisted to promote a masculinist, heteronormative nationalism. While I agree with Judith Halberstam that "a major step toward gender parity, and one that has been grossly overlooked, is the cultivation of female masculinity" (Halberstam 1998:272), I also think that when gender categories are launched into a national imaginary, we need to be concerned about how they are being deployed. What may be a subversive, playfully queer stance in one context may, when magnified, become a neocolonialist position of domination.

Jeanne Hamming argues that a similar sort of nationalistic masculinity is emerging in popular novels about global warming. Examining the global warming novels of Michael Crichton and Kim Stanley Robinson, she argues that "these novels enlist the threat of global warming as yet another occasion to dramatize the recovery of an imperiled national masculinity, adding to the already crowded stage of perceived challenges to the rights and privileges of an elite majority whose supposed "citizen trauma" ... threatens to overshadow the all too real consequences of environmental calamity" (Hamming n.d.). Stunningly, in the face of global environmental disaster, the novels Hamming discusses insist that masculinity is the thing most at risk, the thing we must all clamor to save.

\section{THE META-SCIENCE OF CLIMATE CHANGE AND THE "VIEW FROM NOWHERE"}

Despite the gender panic dramatized by these novels and by the rampant masculinist consumerism of U. S. popular culture, 
another form of hegemonic masculinity lurks in the representations of climate change science. This is the form of masculinity with the most power - the invisible, unmarked, ostensibly perspectiveless perspective. The perspective that need not speak its name. Climate change, as a vast, complex, scientific phenomenon, demands a multitude of mathematical calculations, and not just abstract but virtual conceptualizations. This aspect of global climate change may reentrench traditional models of scientific objectivity that divide subject from object, knower from known, and assume the view from "nowhere while claiming to be everywhere equally" that Haraway has critiqued (Haraway 1991:191). Just when feminist epistemologies and popular epidemiologies are emerging in which citizens become their own scientific experts - within the global campaign against toxins, environmental justice movements, green consumerism, AIDS activism, and feminist health movement - official U. S. representations of global climate change present a transcendent view. Delusions of hyperseparation, transcendence, and dominance only engender denial of the many global environmental crises.

Stunningly, the U. S. Environmental Protection Agency (E.P.A.) website avoids the language of vulnerability, risk, danger, threat, crisis or harm, preferring instead, the bland, innocuous term 'effects', as it casually mentions how rising temperatures "are already affecting the environment." Perhaps these effects will be good, perhaps they will be bad: "The extent of climate change effects, and whether these effects prove harmful or beneficial, will vary by region, over time, and with the ability of different societal and environmental systems to adapt to or cope with the change" (U.S. E.P.A. 2009c). By contrast the World Health Organization begins its discussion of "Climate Change and Human Health": "Climate change is a significant and emerging threat to public health, and changes the way we must look at protecting vulnerable populations" (World Health Organization 2009). Even within the section on "Ecosystems and Biodiversity," the EPA avoids taking any sort of position on whether climate change may be a bad thing:

These changes can cause adverse or beneficial effects on species. For example, climate change could benefit certain plant or insect species by increasing their ranges. The resulting impacts on ecosystems and humans, however, could be positive or negative depending on whether these species were invasive (e.g. weeds or mosquitoes) or if they were valuable to humans (e.g. food crops or pollinating insects) (U.S. EPA, 2009a).

This stance of distant, cold, neutrality, casts uncertainty not as something for which we need to take precautions, but as an ontological state in which all responsibi-lity, all accountability, all values, all risks, are magically erased. Uncertainty in this case does not point to the necessity of the 'precautionary principle', but instead, serves as a prelude to apathy. This is a perfect example of the "social construction of ignorance," in Robert Proctor's terms, the sort of ignorance that has long been manufactured to absolve cigarette companies and chemical manufacturers from blame. "Controversy can be engineered; ignorance and uncertainty can be manufactured, maintain-ed, and disseminated" (Proctor 1996: 8).

While the threat of global climate change and the U.S. responsibility for this threat is conjured away by a bland, free-floating, pervasive uncertainty, a different sort of impassioned voice heralds 'the facts' about a new technology. Under the heading, Fact Sheet: Earth Observation System Will Revolutionize Understanding Of How Earth Works, the EPA casts its faith in a "system of systems" that would finally deliver us complete knowledge, the Global Earth Observation System (GEOS): 
But while there are thousands of moored and free floating data buoys in the world's oceans, thousands of land-based environmental stations, and over 50 environmental satellites orbiting the globe, all providing millions of data sets, most of these technologies do not yet talk to each other. Until they do - and all of the individual technology is connected as one comprehensive system of systems - there will always be blind spots and scientific uncertainty. Just as a doctor can't diagnose health by taking just one measurement, neither can scientists really know what's happening on our planet without taking earth's pulse everywhere it beats - which is all over the globe.

The challenge is to connect the scientific dots - to build a system of systems that will yield the science on which sound policy must be built (U. S. E.P.A. 2009b).

This document poses scientific uncertainty as a momentary obstacle that new technology can fix, rather than something that is endemic to the scientific process and to the nature of the interconnected agencies of human and environmental systems. The analogy of a doctor "taking the earth's pulse," reduces the planet to the size of one familiar being - a patient - who is a passive object of authoritative inquiry. Like magic, almost, science transforms entangled material systems, substances, and agencies into one clear bit of diagnostic data the pulse. Interestingly, this web page offers no visual image of the earth or of this 'system of systems,' leaving us to imagine the doctor patient-scenario or to envision some vast sense of unknowable data finally brought under control by one, single, overarching perspective. By contrast, physicist and historian of science, Spencer R. Weart, argues that "The tangled nature of climate research reflects Nature itself. The Earth's climate system is so irreducibly complicated that we will never grasp it completely, in the way that one might grasp a law of physics" (Weart 2008:ix). And yet the E.P.A. website lists "Nine Societal Benefits" of this system, including: "Understand, Assess, Predict, Mitigate and Adapt to Climate Variability and Change" (U. S. E.P.A. $2009 b)$. The ability to "Understand, Assess, and Predict" global climate change supercedes the goal of reducing climate change. The importance of this system of systems is exaggerated elsewhere on the site. For example, one of the "Substantial Socio-Economic Payoffs" is that "more effective air quality monitoring could provide real-time information as well as accurate forecasts that, days in advance, could enable us to mitigate the effects of poor quality through proper transportation and energy use" (E.P.A. 2009b). Ah well, it 'could', perhaps, if people had alternative systems of transportation or if the government enforced stronger emissions policies for industry. As it stands now, many citizens are simply bewildered by official air quality announcements, which, for example in Texas tell us that it is a 'level orange', 'level red', or even an unthinkable 'level purple' sort of day. More accurate, high-tech, system-ofsystems, air quality pronouncements will not provide citizens with cleaner air or more options for less environmentally harmful transport or energy. The ability to render reality into information, rather than to effect real material change, is the unspoken aspiration. Perhaps it is no oversight, then, that there is no image of the earth on the EPA's climate change web pages. Nina Lykke and Metta Bryld in Cosmodolphins: Feminist Cultural Studies of Technology, Animals, and the Sacred, argue that in NASA's Blue Planet photo: "Nature is being reinterpreted and transformed from object of material consumption to virtual-reality object of worship, awe, and aestheticspiritual consumption" (Bryld and Lykke 2000:6). The generic web pages offered at the Environmental Protection Agency website avoid any invocation of the earth as an object of worship or awe. Instead, science itself, which promises to deliver us utterly disembodied, transcendent, and complete 
knowledge - the system of systems - is venerated and mystified. Perhaps any visual image on these pages would be a sort of idolatry - a 'graven image' that would bring these lofty delusions down to earth. Interestingly, the Group on Earth Observations, the GEO, which was formed in 2002 by the G8, does include an image of the earth, but in this rendition, the oceans are green, the land masses are white, and giant icons that look like game pieces orbit the planet (Group on Earth Observations 2008). ${ }^{5} \mathrm{~A}$ giant ring of icons, adjacent to the globe, labeled "Information for the Benefit of Society," dwarfs the earth. The materiality, the substance, the regional diversity, the geographic diversity, the atmosphere and weather patterns - all substance of the earth itself is erased in this image, as it becomes a blank slate for information. (Information, it must be noted, that will benefit 'society' but not necessarily ecologies, habitats, or nonhuman creatures.) The blankness of the earth's surface makes it seem as if we are waiting for the GEOSS to bring the earth into being - for the scientists to perform an act of creation. The cartoonish game pieces, the technological apparati are the focus here - not the earth itself which has been transmogrified into data divorced from actual places - the oceans are dark green, highlighting the longitudinal and latitudinal lines rather than the water; the land masses are blank. Moreover, we may well ask whether any scientific system even the system of systems - can deliver "Information for the Benefit of Society" which society, whose society? Which members of society will benefit, how will they benefit, and who will be ignored or harmed? This god's eye perspective, this triumphant, purified neutrality, erases social and political contestations, economic disparities, and the material processes of the entangled, emergent world. It imagines that science floats above earthly processes as well as cultural, economic, and political systems. The rhetoric of this system of sy- stems exemplifies the ideal of the "unity of science" that Sandra Harding contends still lurks within the political unconscious of modern science: "its claim that there is just one science that can discover the one truth about nature also assumes that there is a distinctive universal human class - some distinctive group of humans - to whom the unique truth about the world could be evident. However, as feminist and postcolonial thinkers have pointed out, this is no longer a plausible assumption for most of the world's peoples" (Harding 2006:141).

\section{FEMALE VULNERABILITY AND THE MASTERY OF NATURE}

Although the hypermasculine consumerism that has dominated the U. S. in recent decades may seem a far cry from transcendent scientific perspectives, they both detach themselves from vulnerability - precisely the sort of vulnerability that emerges from a serious consideration of how we are all immersed within, rather than floating above, this world. Moreover, the globalizing visions of some of the discourse on climate change impose a rather troubling binary between universal (masculine) scientific knowledge and the marked vulnerability of impoverished women. 'Vulnerability', has, in fact, become a key term in the risk assessments of climate change, where it enables researchers to identify the risk differentials of various groups and regions. Even as it has been important for scholars and women's organizations to assess the ways in which women may be more vulnerable to the effects of climate change, this emphasis on female vulnerability brings at least three problems: 1) it results in a gendered ontology of feminine vulnerability as opposed to the scientific (or masculinist) imperviousness discussed above; 2) it may provoke a model of agency that poses nature as mere resource; and 3) it reinforces, even essentializes gender dualisms in a way that undermines gender and sexual diversity. Even 
as it is crucial to consider the specifically gendered forms of vulnerability that global climate change may exacerbate, a feminist and an LGBT-affirmative ${ }^{5 a}$ politics must avoid reinstalling rigid gender differences and heteronormativity. Moreover, it seems commonsensical to ask that climate change advocacy be environmentally-oriented, in the sense that it should promote the inestimable value, significance and force of ecosystems and natural creatures - not as mere 'resources' for human use, but as truly valuable in and of themselves.

Clearly, many feminist organizations recognize both the power and the risk of the term 'vulnerability', employing it carefully within a context that does not pose women as victims. WEDO, the Women's Environment and Development Organization, which currently focuses on three things climate change, corporate accountability, and governance - charges that gender, "a critical aspect of climate change," "remains largely on the outskirts." Thus, they contend:

Women, as the majority of the world's poor, are among the most vulnerable to the impacts of climate change. They are also critical to climate change solutions. WEDO approaches gender and climate from many angles to ensure that women are present at all levels and dimensions of climate change policy-making and action (WEDO 2004).

Feminist organizations such as WEDO are careful to complement feminine vulnerability with feminist agency, savvy, and survival strategies, calling for more parity in decision making and leadership. For example, the $52^{\text {nd }}$ Session of the United Nations Commission on the Status of Women called attention to the fact that "climate change is not a gender-neutral phenomenon" (52 nd Session 2008). They explain: "given that climate change disproportionately affects the poor, and that women form the majority of the world's poor, women are among the most vulnerable to the effects of climate change" (52nd Session 2008). The report continues to note that "women are particularly vulnerable to natural disasters such as floods, fires, and mudslides," because many girls grow up without learning to swim or climb trees. In addition, climate change threatens women's livelihoods as well as their ability to provide food, water, and fuel for their families. While the first five of the numbered paragraphs stress women's particular vulnerabilities, the eighth point emphasizes women's agency:

[W]omen are not just victims of climate change; they are also powerful agents of change. Women have demonstrated unique knowledge and expertise in leading strategies to combat the effects of climate change, as well as natural disaster management, especially at the grassroots level... [W] vital leadership role in community revitalization and natural resource management. Overall, however, women tend to be underrepresented in decision-making on sustainable development, including on climate change, and this impedes their ability to contribute their unique and valuable perspectives and expertise on the issue (52 nd session 2008).

The next ten of the numbered points - the bulk of the document - lays out strategies for making climate change policies less gender blind, more inclusive, and more equal. This is a comprehensive feminist document, which balances the need to address womens' particular vulnerability to the effects of climate change with a strong statement regarding women's agency, skills, and right of participation.

This particular document, however, severs its feminist position from any sort of environmentalism. 'Nature' is represented here solely in terms of being a resource for domestic use. Although women's distinctive roles in "natural resource management" are mentioned, the interrelations between nature and culture, which are so evi- 
dent within TEK (Traditional Ecological Knowledges), such as the knowledge of traditional medicines, are absent. 'Woman' emerges as a rather monolithic category despite the different examples - constructed at the expense of the values of cultural diversity or biodiversity. For example, they state: "If current global warming trends continue, there will be a significant depletion of fish stock and the coral reef destruction will result in loss of key marine ecosystems that are central to supporting marine resources which comprise a major source of women's livelihoods in the region" (" $52^{\text {nd }}$ Session 2008). There is little sense that the marine ecosystems are valuable in and of themselves, but instead, they are mentioned only because they support the livelihoods of the women. 'Woman', here seems to stake her claims to political agency along a well worn path of masculine hegemonic subjectivity, as outlined by Luce Irigaray, in which nature serves as the background against which her agency and subjectivity may emerge. Similarly, Val Plumwood has identified "backgrounding" as one of the key ways in which the significance of both women and nature have been denied by a male subject who construes "freedom and virtue" in terms of his "control over, and distance from, the sphere of nature, necessity, and the feminine" (Plumwood 1993: 23.) Even as the ubiquitous Western associations between 'woman' and 'nature' have been for the most part quite detrimental to women, feminists who would also be environmentalists need to forge modes of agency that are not predicated upon transcending 'nature'. Considering the widely accepted predictions that global climate change may cause the extinction of one quarter to one third of the world's species by 2050 , nature (the dynamic world of plants, animals, habitats and ecosystems) should be at the foreground - not the background - of climate change policy and politics.
MAINSTREAMING GENDER POLARITIES AND HETERONORMATIVITY

Ironically, some feminist organizations that castigate the gender-blind policies of governing bodies ignore sexual orientation. The "Issues Paper" of the 52nd session of the Commission on the Status of Women on "Gender Perspectives and Climate Change," charges that "there are important gender perspectives in all aspects of climate change" but fails to mention matters of sexual orientation (" $52^{\text {nd }}$ Session 2008). The Global Gender and Climate Alliance, lays out many more categories of concern, acknowledging that "the impacts" of global climate change "will be differentially distributed among different regions, generations, age, classes, income groups, occupations, and between women and men. Poor women and men, especially in developing countries will be disproportionately affected" (Global Gender 2009). But surely people who are marginalized, denigrated, ostracized or criminalized for their sexual orientation or gender identity may be more vulnerable during a national disaster; they may even be blamed or punished for 'causing' the disaster. (In the U.S. for example, gays have been blamed for all sorts of disasters, with the charge that homosexuality incites the wrath of God.) Unfortunately, the very emphasis on gender can erase the existence of GLBT peoples by sedimenting heteronormative gender roles as universal. For example, the United Nations document, Mainstreaming Gender into the Climate Change Regime begins: "The UN is formally committed to gender mainstreaming within all United Nations policies and programmes. In all societies, in all parts of the world, gender equality is not yet realized. Men and women have different roles, responsibilities, and decision-making powers" (United Nations 2004). While it is crucial to address gender-blind science and policymaking this sort of framing casts 'men' and 'women' into clear-cut, universal categories, the objective-sounding state- 
ment declaring that they "have different roles, responsibilities, and decision-making powers" freezes gender polarities in a way that erases social struggle and contestation as well as denying any space at all for those who do not, in fact, fit within these rigid and static categories. 6 Similarly, the Canadian document, Gender Equality and Climate Change, asserts universalized gender differences, untempered by ethnicity, class, culture or sexual orientation: "Women and men experience different vulnerabilities and cope with natural disasters differently; therefore, an increase in the magnitude and frequency of natural disasters will have different implications for men and women" (Canadian International 2009). Feminist organizations, which aim for gender mainstreaming within climate science and policy, may inadvertently be mainstreaming gendered heteronormativity and homophobia by erasing queer people from consideration.

A feminist response to global climate change must not only challenge the impenetrability of big science and the hegemonic masculinity of aggressive consumption but also the tendency to reinforce gendered polarities and heteronormativity. It is my hope that environmental organizations, feminist organizations, activists, (green) consumers, and ordinary citizens will continue to create and transform modes of knowledge, forms of political engagement, and daily practices that contend with global climate change from positions within - not above the vulnerable, yet forceful, ever-emergent world. Perhaps it is possible to foster an insurgent vulnerability that does not entrench gender polarities but instead endorses biodiversity, cultural diversity, and sexual diversity, and recognizes that we all inhabit trans-corporeal interchanges, processes, and flows. We can promote sustainable practices of care and revolt, politics and pleasures.

\section{Notes}

1. I am very grateful to the organizers of the "Gendering Climate and Sustainability" conference for the invitation to speak. I am also grateful to the anonymous reviewers of this essay who provided me with extremely rigorous and challenging readings. (I regret that I do not have the time or space here to contend with all the points they raised.) My thanks to Jeanne Hamming for our discussions of gender and climate change in science and in popular culture. I also thank her for pointing out truck testicles, the existence of which I refused to believe.

la. See Alaimo, "Trans-Corporeal Feminisms and the Ethical Space of Nature" in Alaimo and Hekman, Material Feminismsm and Alaimo, Bodily Natures: Science, Environment and the Material Self.

2. For more on naked protesting see Alaimo, 2010.

3. Greenpeace serves as a striking example of how activists can engage with environmental science and yet resist the transcendent vision often promoted by authoritative scientific accounts, fostering instead, a recognition of the human as immersed within environments. In their campaign against mercury, for example, they asked ordinary people to send in samples of their hair for scientific testing, providing individuals with the data about their exposure to mercury as well as listing both political and practical ways to reduce exposure to mercury.

4. As one of the anonymous readers points out, it is important to consider that there are particularly female, feminine, and feminized modes of consumption that greatly contribute to global climate change. This is certainly true but cannot be accounted for within this essay. See Kate Soper's essay within this volume.

5. See: http://www.earthobservations.org/ geoss.shtml

5a. LGBT: Lesbians, Gays, Bi-sexuals, Transexuals. 6. "The human potential for incredibly precise classifications has been demonstrated in multiple arenas: why then do we settle for a paucity of classifications when it comes to gender. .. . The point here is that there are many ways to depathologize gender variance and to account for the multiple genders that we already produce and sustain" (Halberstam 27). 


\section{LITERATURE}

- Adler, Esther (2008): “Kirsten Justesen: My

Body as Material: Danish artist

- Kirsten Justesen speaks with MoMA Curatorial

Assistant Esther Adler", in P.S.1Newspaper.

http://psl.org/newspaper/view/article/15, accessed March 1, 2009.

- Adler, Margo (2006): "Behind the Ever Expanding American Dream House", in All Things Considered. July 4. National Public Radio.

http://www.npr.org/templates story/

story.php? storyId $=5525283$, accessed April 20, 2009.

- Alaimo, Stacy (2008): “Trans-Corporeal Feminisms and the Ethical Space of Nature", in Stacy Alaimo and Susan Hekman (eds.): Material Feminisms, Indiana University Press, Bloomington. - Alaimo, Stacy (2010a): Bodily Natures: Science, Environment, and the Material Self. Indiana University Press, Bloomington.

- Alaimo, Stacy (2010b): "The Naked Word: The Trans-corporeal Ethics of the Protesting Body," forthcoming in Women \& Performance.

- Bryld, Mette and Nina Lykke (2000): Cosmodolphins: Feminist Cultural Studies of Technology, Animals and the Sacred. Zed Books, London.

- Canadian International Development Agency (2009): "Gender Equality and Climate Change," http://www.acdicida.gc.ca/INET/IMAGES.NSF /vLUImages/Climate\%20chage $3 /$ file/Gender-

2.pdf accessed March 8, 2009.

. $52 \mathrm{nd}$ Session of the Commission on the Status of Women (2008): "Gender Perspectives on Climate Change: Issues Paper.” Thursday February 28, United Nations, New York. 2008

http://www.un.org/womenwatch/daw/csw/csw 52 /issuespapers/Gender\%2

and $\% 20$ climate $\% 20$ change $\% 20$ paper $\% 20$ final.pdf (accessed March 8, 2009).

- Global Gender and Climate Alliance (2009):

"Launch of the Global Gender and Climate Alliance." http://www.wedo.org/wp-content/uploads/global-gender-and-climate-alliance.pdf, accessed March 8, 2009.

- Group on Earth Observations (2008): "What is GEOSS: The Global Earth Observation System of Systems," http://www.earthobservations.org/ geoss.shtml, accessed April 20, 2009.

Halberstam, Judith (1998): Female Masculinity. Duke University Press, Durham.

- Hamming, Jeanne (n.d.): "Engendering Global Climate Change: Masculinity and the Politics of Nature in the Novels of Kim Stanley Robinson and Michael Crichton," unpublished manuscript. - Haraway, Donna (1991): "Situated Knowledges:
The Science Question in Feminism and the Privilege of Partial Perspective" in Donna Haraway, Simians, Cyborgs, and Women: The Reinvention of Nature. Routledge, New York.

- Harding, Sandra (2006): Science and Social Inequality: Feminist and Postcolonial Issues. University of Illinois Press, Urbana.

- Intergovernmental Panel on Global Climate Change (IPCC) (2007): “Climate Change 2007: Impacts, Adaptation and Vulnerability." http://www.ipcc.ch/

- Jeffords, Susan (1994): Hard Bodies: Hollywood Masculinity in the Reagan Era. Rutgers University Press, New Brunswick.

- Mann, Bonnie (2006): "How America Justifies its War: A Modern/Postmodern Aesthetics of Masculinity and Sovereignty", in Hypatia 21.4, Fall 2006.

- Plumwood, Val (1993): Feminism and the Mastery of Nature. Routledge, New York.

- Proctor, Robert N. (1996): Cancer Wars: How Politics Shapes What We Know and Don't Know about Cancer. Basic Books, New York.

. "600 strip naked on glacier in global warming protest: Chilling message from wear-nothing activists to do-nothing politicians" (2007): Greenpeace International web site. August 18, 2007. http://www.greenpeace.org/international/news/ naked-glacier-tunick 08182007 accessed February, 21, 2009.

- United Nations (2004): "Mainstreaming Gender into the Climate Change Regime" 14 December 2004 ,COP10 Buenos Aires.

http://www.genanet.de/fileadmin/downloads/St ellungnahmen_verschiedene en/Gender_and_climate_change_COP10, accessed March 8, 2009.

- United States Environmental Protection Agency (2009a): "Ecosystems and Biodiversity."

http://www.epa.gov/climatechange/effects/eco. html, accessed March 6, 2009.

- United States Environmental Protection Agency (2009b): "Global Earth Observation System of Systems (GEOSS)".

http://www.epa.gov/geoss/fact_sheets/earthobservation.html accessed March 8, 2009.

- United States Environmental Protection Agency (2009c): "Health and Environmental Effects." In "Climate Change." http://www.epa.gov/climatechange/effects/index.html. Accessed April 20, 2009.

- Weart, Spencer R. (2008): The Discovery of Global Warming. Revised and Expanded Edition. Harvard University Press, Cambridge.

- Women's Environment and Development Organization (WEDO) (2004): "Climate Change." 
New York, http://www.wedo.org/category/ learn/campaigns/climatechange, accessed April $20,2009$.

- World Health Organization (2009): "Climate Change and Human Health"

http://www.who.int/globalchange/climate/en/, accessed March 6, 2009.

\section{SUMMARY}

Gendered stances, styles, practices, and modes of thought permeate the representations of the science of climate change, the activist response to climate change, and modes of consumerism responsible for releasing massive quantities of carbon into the atmosphere. This article critiques two predominant forms of masculinity
- the masculinity of aggressive consumption that has increased the carbon footprint of the U.S. and the free-floating, transcendent perspective presented by the official U.S. accounts of climate change. The article argues that a stance of 'insurgent vulnerability' counters the sense of enclosed imperviousness proffered by both masculinist consumerism and abstract technological perspectives. It concludes with a note of caution about the term 'vulnerability' which may reinforce gender dichotomies, heteronormativity, and the reduction of the environment to a 'resource'.

Stacy Alaimo

University of Texas

Associate Professor of English

University of Texas at Arlington 